\title{
Os Três Momentos Pedagógicos como Estruturantes de Currículos: Algumas Potencialidades
}

\section{The Three Pedagogical Moments as Structurants of Curriculums: Some Potentialities}

\section{Laís Baldissarelli de Araújo ${ }^{a}$; Cristiane Muenchen ${ }^{a}$}

a Departamento de Física, Universidade Federal de Santa Maria, Santa Maria, Brasil - lais_baldissarelli@yahoo.com.br, crismuenchen@yahoo.com.br

\section{Palavras-chave: Currículo. Três momentos pedagógicos. Problematização. Diálogo. Paulo Freire.}

\section{Keywords:}

Curriculum. Three pedagogic moments. Problematization. Dialogue. Paulo Freire.
Resumo: Procura-se, com o presente artigo, destacar as potencialidades encontradas por professoras de uma escola pública estadual de Santa Maria/RS ao utilizarem a dinâmica dos Três Momentos Pedagógicos (3MP) para a organização curricular e também como ferramenta didático-pedagógica em sala de aula. Os instrumentos utilizados na coleta de informações foram: questionário, diários da prática pedagógica das docentes, diários da pesquisadora, entrevistas semiestruturadas e análise documental dos planejamentos das aulas. A metodologia utilizada para análise dos dados foi a Análise Textual Discursiva (ATD). Nas potencialidades, agruparam-se características como: a participação, a problematização e o diálogo construído entre educador-educandos e a relevância do processo formativo realizado.

Abstract: This present article aims to highlight the potentialities found for teachers in a state public school from Santa Maria in Rio Grande do Sul, where they used three pedagogical moments dynamics to the curricular organization and also as didactic - pedagogical tool in the classroom. The tools used in the collect of information were: questionnaires, teachers' pedagogical practice books, the researcher's books, semi-structural interviews and documentary analysis of the classes planning. The methodology used to the data analysis was the discursive textual analysis. In the potentialities, grouped characteristics like: the participation, the problematization and the dialogue built between teacher-students, and the relevance of the formative process accomplished. 


\section{Introdução}

Torna-se importante a realização de novas alternativas no âmbito educacional, pois este vem tornando-se pauta de grandes discussões nos últimos tempos, sendo alarmantes os resultados apresentados nas escolas, em que o índice de evasão, o desinteresse e a repetência dos educandos, bem como a desmotivação dos mesmos, vêm aumentando de forma exponencial (SÃO PAULO, 1990; MUENCHEN, 2006; LINDEMANN, 2010; HALMENSCHLAGER, 2014).

Destas discussões resultam como possíveis soluções para esses problemas novas metodologias para o ensino. Porém, estas soluções serão válidas somente quando o que antecede as metodologias e ferramentas for rediscutido e alterado, ou seja, os programas escolares, os currículos.

Delizoicov (1982), Delizoicov et al. (2011), Muenchen (2006), Muenchen e Auler (2007a), Torres et al. (2002) e Muenchen (2010) são alguns dos autores que destacam a necessidade de mudanças nos programas curriculares das escolas, ressaltando que a construção destes currículos ocorre, na maioria das vezes, de forma que educadores e educandos não participam deste processo, tendo suas funções restritas apenas a executores e espectadores dos programas.

Partindo das necessidades de mudança, é apresentada a dinâmica dos Três Momentos Pedagógicos (3MP), resultante da concepção freireana para o contexto da educação formal, sendo desenvolvida, inicialmente, por Delizoicov (1982), estando fundamentada pela Abordagem Temática (DELIZOICOV et al., 2011).

Muenchen (2010), em sua tese de doutorado, destaca que a prática de sala de aula como a organização curricular tem uma relação dinâmica, dessa forma, os 3MP podem guiar a estruturação do currículo, como também a implementação do mesmo em sala de aula. A autora enfatiza, ainda, a importância da continuação dos estudos de como a dinâmica dos 3MP vem sendo utilizada em outras localidades brasileiras, bem como aprofundar, a partir de processos formativos, como os educadores da região investigada em sua tese, Santa Maria/RS, estão enfrentando os aspectos referentes ao "como ensinar" e "o quê" ensinar. Neste sentido, emerge o problema de pesquisa deste artigo: Quais as potencialidades encontradas por professores de uma escola pública estadual de Santa Maria/RS ao utilizar a dinâmica dos 3MP para a organização curricular e também como ferramenta didáticopedagógica em sala de aula?

\section{Referencial teórico}

Os 3MP, por incorporarem a concepção dialógica e problematizadora de Paulo Freire (2011), se desenvolvidos de forma dialógica e a partir da realidade do educando, podem 
fortalecer o processo de ensino/aprendizagem, contribuindo para o desenvolvimento do senso crítico e para a superação dos níveis de consciência pelo educando (GIACOMINI, 2014).

Com a disseminação dos 3MP e o avanço de seus significados durante os projetos denominados "Formação de Professores de Ciências Naturais" (DELIZOICOV 1980, 1982), "Ensino de Ciências a Partir de Problemas da Comunidade" (PERNAMBUCO, 1994) e "Interdisciplinaridade via Tema Gerador" (TORRES et al., 2002) este último conhecido também como Projeto Inter ou Movimento de Reorientação Curricular (MRC), os momentos pedagógicos extrapolaram a sua utilização inicial, ampliando seu emprego no processo dinâmico como um todo.

Neste último projeto, os 3MP estavam presentes em todas as etapas do desenvolvimento, ou seja, eram utilizados como estruturantes dos currículos para a definição dos temas a serem trabalhados nas escolas e como dinâmica para a elaboração dos planejamentos das áreas, das disciplinas e no desenvolvimento das atividades em sala de aula, conforme é apontado por Muenchen:

[...] os 3MP estavam implícitos em todos os aspectos pedagógicos do Projeto Inter, ou seja, não apenas revelavam a forma como os professores formados conduziam seus esforços na construção curricular como também constituíam a estrutura que guiava o processo como um todo. Logo, pode-se afirmar que os três momentos orientavam tanto o desenvolvimento curricular geral como o trabalho específico de sala de aula (2010, p. 120).

No MRC, os 3MP foram utilizados inicialmente como estruturantes de currículos, demonstrando, com isso, as diversas possibilidades e formas de utilização que esta dinâmica proporciona, destacando a necessidade de que todos os sujeitos envolvam-se de maneira ativa no processo de ensino/aprendizagem, valorizando o papel do professor, bem como do educando, em que estes são atores principais no processo de construção do conhecimento baseado na coletividade, no diálogo e na problematização. Como estruturantes de currículos, os momentos pedagógicos são conhecidos como:

Estudo da Realidade (ER): Este primeiro momento pedagógico do desenvolvimento curricular é destinado a obter informações sobre a comunidade na qual está inserida a escola. Esta investigação ocorre a partir de um dossiê que contém entrevistas, questionários, conversas informais, análises de documentos, visitas a igrejas, centros comunitários, IBGE. Ainda, são investigados os interesses, objetivos, expectativas da comunidade escolar. Num segundo momento, os docentes no coletivo codificam as situações significativas obtidas do dossiê e, como resultado chega-se ao tema gerador em torno do qual será construído o currículo da escola (MUENCHEN, 2010; MUENCHEN; DELIZOICOV 2012; ARAÚJO; MUENCHEN, 2013a).

Sampaio, Quadrado e Pimentel destacam que: 
O tema gerador, proposto inicialmente pelo educador Paulo Freire, é entendido como um objeto de estudo que compreende "o fazer e o pensar, a ação e a reflexão, a teoria e a prática", assim como um caminho para reorientar de forma interdisciplinar o currículo (1994, p.59).

Paulo Freire, em seu livro intitulado Pedagogia do Oprimido (2011), apresenta o processo de Investigação Temática, o qual procura, a partir dos temas geradores, dialogar e problematizar a realidade concreta, a situação presente e existencial na qual os educandos encontram-se imersos, buscando, com isso, a partir do conhecimento crítico das situações analisadas, a transformação destas situações.

Neste sentido, os temas geradores resultantes deste processo são responsáveis pela organização dos conteúdos programáticos a serem trabalhados na perspectiva da educação dialógica e problematizadora. Freire destaca que o trabalho a partir do tema gerador necessita que o educador deva:

[...] propor ao povo, através de certas contradições básicas, sua situação existencial, concreta, presente, como problema que, por sua vez, o desafia e, assim, lhe exige resposta, não só no nível intelectual, mas no nível da ação (Ibid., p. 120).

Organização do Conhecimento (OC): Neste momento, são utilizados os dados que emergiram do ER para que o coletivo de professores possa definir quais serão as questões geradoras e os conteúdos específicos que deverão ser trabalhados para a compreensão do tema gerador. Este momento destina-se aos planejamentos por áreas (MUENCHEN, 2010; MUENCHEN; DELIZOICOV, 2012; ARAÚJO; MUENCHEN, 2013a).

Aplicação do Conhecimento (AC): O terceiro momento pedagógico é destinado à implementação das atividades em sala de aula e à avaliação do programa, avaliação caracterizada também pela "planificação de actividades que demonstrem as construções de conhecimento" (TORRES et al., 2002, p. 148).

Com o desenvolvimento do Projeto Inter, foi possível constatar que não somente os planejamentos das aulas podem estar estruturados a partir dos 3MP, mas também o currículo escolar, possibilitando que este seja construído de forma interdisciplinar e dialógica a partir de problemas que estão em contato com os educandos. Com isso, ao explorar a realidade concreta dos educandos, tornando-a objeto de estudo, possibilita-se que seja aguçada a curiosidade epistemológica dos educandos (FREIRE, 1992), dimensão central no ato de aprender, fortalecendo o processo de ensino/aprendizagem e estimulando a cultura de participação.

Neste mesmo sentido, os 3MP por originar-se de uma transposição da concepção freireana para o contexto de educação formal e por estar fundamentado na perspectiva da abordagem temática, apresenta como princípios fundamentais a problematização, a dialogicidade e o trabalho coletivo e interdisciplinar, sendo estas categorias defendidas por Freire. 
Nos 3MP, a problematização está implícita em todos os momentos, pois busca, a partir de aspectos relacionados à vida dos educandos, discutir, investigar, dialogar, problematizar tais situações. Muenchen e Delizoicov destacam a presença da problematização na dinâmica dos 3MP:

[...] trata-se de uma prática didático-pedagógica que, tendo como fundamentos a dialogicidade e a problematização, conforme consideradas por Freire (1987), possibilita a presença constante e sistematizada de elementos de situações significativas oriundas do local em que vive a população que envolvem contradições, para que sejam sistemáticas as problematizações das compreensões dos alunos sobre elas, obtidas através das suas "falas" (2012, p. 14).

Muenchen (2010) aponta, ainda, que a problematização é uma forma de desvelamento, pois a partir dela o professor problematizador não descreve os conteúdos, mas sim desvela-os para que os educandos queiram conhecer. Com isso, a problematização provoca a curiosidade e o querer conhecer. Neste sentido, a autora assinala a importância da problematização na utilização dos 3MP:

Ao problematizar, de forma dialógica, os conceitos são integrados à vida e ao pensamento do educando. Ao invés da memorização de informações [...] ocorre o enfrentamento dos problemas vivenciados. Em síntese, a problematização pode possibilitar que os educandos tornem-se críticos das próprias experiências (2010, p. $160)$.

Araújo et al. (2013) ressaltam uma das diferenças entre a problematização e a pergunta, aspecto muito importante que deve ser compreendido. Em uma problematização, abrem-se caminhos para o diálogo, já que esta contribui para que os alunos tornem-se curiosos pelas questões lançadas, diferenciando-se de uma pergunta, na qual estes, na maioria das vezes, simplesmente respondem, sem sentirem-se desafiados por elas.

A dialogicidade, assim como a problematização, está incorporada em cada um dos momentos pedagógicos, pois esta dinâmica busca com o educando a construção de soluções para os problemas emergentes da vida dos mesmos, possibilitando que eles pronunciem-se e exponham suas opiniões, dúvidas e anseios. Segundo Pernambuco (1994), o diálogo propicia uma interação constante, permitindo que, a todo o momento, façam-se ajustes na programação, impossibilitando, assim, que o programa torne-se estanque e acabado.

Delizoicov destaca a compreensão daqueles que trabalham por uma educação com o educando e não para o educando, em relação à prática da dialogicidade:

O diálogo, como está sendo colocado, [...] transcende o simples "conversar" com o aluno, ou o simples "deixar" que o aluno fale. Entendemos que ele não se limita apenas à situação "sala de aula", pelo contrário, ali ele deverá ser a continuidade do diálogo iniciado com os "representantes da comunidade" (1982, p. 15).

A partir do diálogo entre os sujeitos, busca-se a reflexão e a ação, a práxis, dos temas problematizados no processo de ensino/aprendizagem, tendo os educandos, conforme aponta Muenchen (2010), vez e voz para exporem seus pensamentos e opiniões referentes ao assunto abordado. Assim, o diálogo possibilita que o educando sinta-se desafiado, inquieto, instigado 
em expor suas ideias e dúvidas na busca de um pensar crítico que possibilite a mudança, a partir dos temas significativos que estão sendo trabalhados.

Por fim, o trabalho desenvolvido a partir dos 3MP tem por objetivo problematizar, a partir do diálogo, o mundo da vida dos educandos. Esta dinâmica busca a participação de todos os sujeitos na construção dos programas, necessitando, para isso, o trabalho coletivo. Com isso, na dinâmica dos 3MP, a interdisciplinaridade tem um papel importante, pois, com esta dinâmica, as práticas educativas são construídas por equipes de professores que, no coletivo, procuram incorporar informações das disciplinas necessárias para que seja possível a compreensão do tema abordado, distanciando-se, assim, da visão fragmentada no processo de construção do conhecimento em que cada disciplina tem papel isolado.

\section{Procedimentos metodológicos}

Conforme aponta Muenchen (2006), o atual processo de ensino/aprendizagem de Ciências/Física tem apresentado limitações e/ou problemas a serem enfrentados, tais como: a fragmentação disciplinar; a desmotivação dos alunos; a desvinculação entre o "mundo da escola" e o "mundo da vida"; o ensino propedêutico; a falta de consideração pela complexidade do mundo real; e, possivelmente vinculado a todos estes aspectos, um baixo nível de aprendizagem, assim como limites à formação de uma cultura de participação.

Buscando superar tais limitações, o objetivo do presente artigo, que emerge de uma pesquisa mais ampla em nível de mestrado (ARAÚJO, 2015), na qual foi desenvolvido um processo formativo e coletivo com docentes de Física e Matemática de uma escola pública estadual de Santa Maria/RS, concentra-se em analisar as potencialidades encontradas por estas docentes, ao utilizarem a dinâmica dos 3MP para a organização curricular e também como ferramenta didático-pedagógica em sala de aula.

A presente pesquisa fundamenta-se, segundo Gil (2002), numa abordagem de cunho qualitativo e exploratória. Para a coleta dos dados, foram utilizados questionários, entrevistas realizadas com as docentes e com os alunos ao final do projeto, análise documental dos planejamentos das aulas, análise do Projeto Pedagógico (PP) da escola, diários da prática pedagógica das docentes e diários da pesquisadora, adaptados de Porlán e Martín (1997). Para análise dos dados obtidos, utilizou-se a Análise Textual Discursiva (ATD) (MORAES; GALIAZZI, 2007).

Procurou-se, com o desenvolvimento desta pesquisa, possibilitar que educadoras de uma escola pública da rede estadual da periferia da zona sul de Santa Maria/RS percebessem que o seu papel docente extrapolava os limites da sala de aula. Para isso, realizou-se um curso de formação de 40 h com o objetivo de estruturar o currículo da escola por meio dos 3MP de 
forma coletiva e interdisciplinar ${ }^{1}$. O convite para participação do curso estendeu-se a todas as áreas de ensino, visto que, o mesmo visava o trabalho coletivo e interdisciplinar, porém, participaram do curso 3 (três) docentes: 2 (duas) professoras da disciplina de Física e 1 (uma) professora da disciplina de Matemática.

Inicialmente, a escolha pela escola que foi implantado o projeto ocorreu em função de esta escola estar inserida em uma região da cidade de Santa Maria que enfrentava muitos problemas sociais e estruturais. Ademais, a opção por esta escola aconteceu também pelo fato desta apresentar como metas alguns aspectos que se entrelaçam com os objetivos da pesquisa, bem como de seu referencial teórico, como é possível de analisar-se no Projeto Pedagógico (PP) da mesma:

Realizar um trabalho interdisciplinar através de uma organização curricular diferenciada; Propor um processo avaliativo que rompa com o modelo tradicional; Manter uma relação professor aluno que valorize as experiências, respeite as limitações e ajude no crescimento humano e social; Proporcionar formação continuada para os professores buscando, a melhoria da qualidade docente; Planejar atividades sociais e culturais que possibilitem ao aluno tomar contato com diferentes meios de convivência; Manter um diálogo aberto com toda a Comunidade Escolar; [...] Adquirir bens materiais, na medida do possível, para subsidiar os professores; [...] Proporcionar um horário de planejamento semanal para todos os professores (PP, 2011, p. 9).

Buscou-se, com o desenvolvimento da pesquisa desenvolvida, possibilitar que as docentes da escola, percebessem que o seu papel docente extrapolava os limites da sala de aula. Com isso, Araújo (2015) destaca a necessidade do contato das docentes com a realidade dos educandos, possibilitando um contato mais próximo com a realidade que os cercam. $\mathrm{Na}$ sequência, é apresentado um trecho da entrevista realizada com as docentes que manifesta esta aproximação:

Eu acho que embora eu não me achasse tão longe deles, eu acho que essa maior aproximação foi que me levou a discutir situações da vida deles, que se eu não tivesse ido à comunidade eu não saberia né, como essa fragilidade social que eles têm. E aí, eu acho que forço uma aproximação maior, e essa aproximação maior tornou eles mais receptivos [...] (Prof. 1).

Para a realização do ER, o coletivo de docentes confeccionaram materiais para a construção do dossiê, sendo realizadas entrevistas com a comunidade local de onde os educandos emergiam (comerciantes, pais dos educandos, moradores do bairro), com o posto de saúde da comunidade, com a equipe diretiva da escola, professores, funcionários da escola, estudantes. Foram realizadas ainda conversas informais, análise de fotografias e documentos. Destaca-se que este processo foi realizado pelas docentes participantes do curso, sendo que os estudantes não participaram efetivamente do mesmo, pois o foco do trabalho concentrou-se

\footnotetext{
${ }^{1}$ Torna-se válido destacar aqui, a compreensão do que é interdisciplinaridade para os autores. Estes acreditam que a compreensão sobre interdisciplinaridade está relacionada à necessidade das disciplinas estarem trabalhando de forma coletiva para a compreensão de um determinado tema, não sendo, por vezes, obrigatório a presença de todas as disciplinas.
} 
em romper as barreiras da sala de aula destas docentes, adentrando na comunidade bem como na realidade de seus educandos.

Após o contato com a comunidade local e escolar, o coletivo de professoras categorizou as informações obtidas e, as situações significativas que resultaram deste processo foram drogas, segurança, transporte, saúde, rede de esgoto e lixo emergindo assim, o tema a ser trabalhado: Infraestrutura (ARAÚJO, 2015). Aponta-se neste momento, que o processo de categorização das falas emergentes da comunidade local e escolar e do material analisado não foram apresentadas neste artigo, visto que o objetivo central do mesmo não é relatar como realizou-se o Estudo da Realidade mas sim, destacar as potencialidades encontradas por professoras ao utilizarem a dinâmica dos 3MP como estruturadores de currículos bem como na ferramenta didático-pedagógica.

Com o desenvolvimento do tema Infraestrutura, buscou-se discutir com os educandos os problemas que a comunidade apresentava e, a partir das discussões e das atividades realizadas, possibilitar que estes sujeitos tornem-se capazes de intervir e modificar a sociedade que os cercam.

Segundo Araújo e Muenchen (2014), o tema Infraestrutura por emergir da Investigação Temática, o qual apresenta os problemas da comunidade dos educandos, é caracterizado como sendo um tema gerador ${ }^{2}$ (FREIRE, 2011) além de que, este tema apresenta outros subtemas inseridos em seu interior que possibilitam novas discussões para a compreensão de outras situações. O tema, de fato, é caracterizado como gerador por apresentar manifestações locais da realidade concreta dos educandos, propiciando, com isso, um estímulo ao que Freire (1992) denomina de curiosidade epistemológica, dimensão central no ato de aprender, fortalecendo o processo de ensino/aprendizagem e estimulando a cultura de participação.

Após a determinação do tema "Infraestrutura", encaminharam-se os outros dois momentos, ou seja, a OC e a AC. Destaca-se que, após a obtenção do tema, foram direcionados os planejamentos das aulas e a implementação das mesmas, com base na dinâmica dos 3MP.

\section{Resultados e discussões}

Neste artigo focalizou-se a categoria representativa das potencialidades, a qual se originou do processo de ATD em que foram analisados os instrumentos utilizados na coleta de dados, bem como o Projeto Pedagógico da escola, constituindo assim o corpus de análise,

\footnotetext{
${ }^{2}$ Para Freire "estes temas se chamam geradores porque, qualquer que seja a natureza de sua compreensão, como a ação por eles provocada, contêm em si a possibilidade de desdobrar-se em outros tantos temas que, por sua vez, provocam novas tarefas que devem ser cumpridas" (2011, p. 130).
} 
conforme caracteriza Moraes (2003). Após a unitarização das informações, resultaram duas categorias: Do processo formativo à implementação das aulas na perspectiva dos 3MP: algumas potencialidades e $\mathrm{O}$ processo formativo e a implementação das aulas a partir da dinâmica dos 3MP: desafios a serem enfrentados. Destaca-se que neste artigo, será focalizada apenas a categoria Do processo formativo à implementação das aulas na perspectiva dos 3MP: algumas potencialidades, sendo que esta categoria originou-se das subcategorias: $A$ importância do curso proposto a partir da dinâmica dos 3MP frente às necessidades impostas pelas docentes na qual destaca as necessidades que as docentes enfrentavam, diante de suas práticas pedagógicas, que foram supridas com a utilização dos 3MP; $A$ problematização defendida por Paulo Freire em consonância com os 3MP: a presença do contexto dos educandos nas práticas desenvolvidas, sendo esta a subcategoria que apresentou a importância quanto ao reconhecimento do contexto dos educandos diante das práticas elaboradas a partir dos 3MP, no qual se encontra em consonância com a problematização abordada por Paulo Freire; Por fim, a subcategoria $O$ diálogo problematizador como potencializador da participação e do interesse dos educandos com base nos 3MP aborda a nova postura apresentada pelos educandos a partir do diálogo problematizador - eixo central na dinâmica dos 3MP.

\section{Do processo formativo à implementação das aulas na perspectiva dos 3MP: algumas potencialidades}

Esta categoria apresenta os aspectos positivos apresentados diante dos instrumentos de análise. Destaca-se, nesta categoria, as potencialidades quanto a dinâmica adotada no trabalho desenvolvido, a postura apresentada pelos educandos, e também os avanços diante do trabalho interdisciplinar e coletivo apresentados pelas participantes do curso. É importante ressaltar que neste artigo não foram abordados os desafios, como é o caso das condições de trabalho das docentes, sendo este, foco de análise de um trabalho futuro.

\section{A importância do curso proposto a partir da dinâmica dos 3MP frente às necessidades impostas pelas docentes}

Sendo o objetivo principal do curso de formação ministrado (ARAÚJO, 2015) construir de forma coletiva e interdisciplinar com as professoras participantes, a partir da dinâmica dos 3MP, o currículo da escola baseado na realidade vivida dos educandos e, com isso, elaborar os planejamentos didáticos interdisciplinarmente para posterior implementação, apontou-se a necessidade, por elas destacadas no primeiro encontro, de conhecer um trabalho que abarcasse a interdisciplinaridade e que estimulasse a participação dos estudantes através de temas que fossem relevantes a estes, possibilitando, com isso, aproximar-se dos objetivos 
que a escola apresenta. Isto pode ser verificado nas falas das docentes e também em um trecho do diário da pesquisadora:

Aprender, por que tenho a impressão que "falta perna" para continuar o trabalho (Prof. 1).

Aprender novas práticas para ensinar [...] (Prof. 2).

Que o curso venha preencher um pouco mais nossos conhecimentos, através de diálogos, e como é o dia-a-dia, na prática (Prof. 3).

[...] questionei quais eram as expectativas pelo curso, o que era esperado do trabalho. A professora 1 de física disse que buscava o curso, pois este vinha ao encontro do que a proposta da escola buscava, um trabalho interdisciplinar e um planejamento através de temas, além de que conhece a dinâmica dos 3MP e se interessou pelo curso por apresentar um trabalho mais amplo, a partir dos momentos pedagógicos. A professora 2 de matemática falou que se interessou pelo curso, pois acredita que este irá agregar muito em sua trajetória, porque percebe a dificuldade que é trabalhar de forma interdisciplinar e acredita que, com o curso, isso será mais fácil acontecer. A professora 3 de física ressalta que busca no curso algo que proporcione ao aluno um interesse pelas aulas, pois os mesmos estão muito desmotivados e desinteressados (DIÁRIO DA PESQUISADORA, 31/08/2013).

É possível constatar que existe uma lacuna na formação docente, principalmente das professoras 2 e 3, tratando-se de aspectos que remetem a aprendizagem voltada para o educando, em que a interdisciplinaridade tem papel fundamental e o diálogo torna-se um articulador na construção do conhecimento. Neste sentido, a falta de compreensão de determinados aspectos, tais como, currículo, interdisciplinaridade, trabalho coletivo, durante a formação docente acabou, por vezes, dificultando a implementação de um currículo diferenciado, como, por exemplo, um currículo baseado em temas, em que o diálogo, a problematização, a interdisciplinaridade, o envolvimento de todos os sujeitos a partir do trabalho coletivo são premissas básicas.

Para que situações como estas sejam minimizadas, conforme aponta Delizoicov (2008), seria relevante incorporar disciplinas nos cursos de licenciaturas que abordassem visões de uma educação voltada para os educandos, em que o trabalho coletivo e interdisciplinar se tornasse aspectos fundamentais num processo de construção do conhecimento conjunto entre educador e educandos. Neste sentido, Sauerwein (2008) aponta para a necessidade de que os cursos de formação continuada sejam reavaliados e reestruturados, articulando os pressupostos atuais de ensino sobre o papel do professor no processo de ensino/aprendizagem, evitando a reprodução e a transmissão dos conhecimentos aos docentes em que os conteúdos apresentados são apenas "despejados" e isolados de uma discussão e construção coletiva, a qual pode possibilitar uma reflexão crítica acerca dos assuntos abordados (SAUERWEIN, 2008).

Dentre os objetivos propostos, buscava-se, a partir dos 3MP, um currículo em que o educando encontrava-se no centro do processo de sua aprendizagem, possibilitando a 
compreensão e o posicionamento do estudante quanto aos problemas vivenciados por ele, sendo estes problemas/temas os estruturantes do currículo construído pelos 3MP.

É possível constatar, a partir das entrevistas realizadas com as professoras e educandos, que os 3MP potencializaram e possibilitaram que o estudante tivesse papel central no processo de sua construção do conhecimento:

\begin{abstract}
Principalmente porque ela deixava a gente falar, colocar nossas opiniões também. O que mais me chamou atenção foi isso, a gente podia falar bastante, não era só ficar ouvindo, ouvindo, ouvindo (Aluno 1).

Participativa, por que mais gente interage né, por ser por debate. Não precisa ter todo o conhecimento, antes pra ti poder falar, tu tinha que saber né, e no debate não, tu pode falar o que tu acha. E depois do debate a gente fazia as atividades que eram propostas (Aluno 2).

[...] deixamos espaço para debate, onde cada aluno compartilhou suas vivências e houve uma grande participação, pois todos de algum modo sofrem com os danos causados ao Arroio Cadena, seja pelos problemas causados pelas chuvas ou mesmo com os problemas de saúde (Prof. 2, Diário de aula).
\end{abstract}

Houve bastante diferença, essa maneira de trabalhar assim com eles né, até eu tinha falado para minha colega de adotar nas outras turmas essa dinâmica de ter os alunos mais perto da gente (Prof. 3).

Algumas pesquisas desenvolvidas já apontavam para esta potencialidade. Giacomini (2014), ao desenvolver um trabalho com os professores de uma escola pública de ensino médio, onde estes implementaram intervenções curriculares a partir da abordagem temática em turmas do ensino médio regular e da Educação de Jovens e Adultos (EJA) verificou que os educandos apresentaram posturas próximas as citadas acima. Araújo e Muenchen (2013b), ao discorrerem sobre o trabalho implementado em uma turma da EJA, durante o estágio supervisionado, a partir do tema "Sol, Luz e Vida", destacam a postura de participação e interesse pelos educandos e, Muenchen e Auler (2007b) apontam a participação dos educandos nas aulas desenvolvidas pela intervenção realizada a partir da abordagem temática que buscava enfocar as interações entre Ciência, Tecnologia e Sociedade (CTS).

As posturas apresentadas acima, em que a participação do educando, a proximidade com o docente e o diálogo construído podem ser consideradas potencialidades em relação ao comportamento e à participação que são apontados quando o assunto remete ao interesse e ao envolvimento dos educandos em sala de aula. Relacionam-se estas potencialidades à dinâmica dos momentos pedagógicos, pois, quando se trabalha com esta perspectiva, os temas abordados são relevantes aos educandos e é dado espaço para a construção dialógica entre educador-educando. 


\section{A problematização defendida por Paulo Freire em consonância com os 3MP: a presença}

\section{do contexto dos educandos nas práticas desenvolvidas}

Ao problematizar-se um tema que se encontra inserido na vida dos educandos, o "mundo da vida" adentra o "mundo da escola" e proporciona-lhes a participação, o diálogo e o interesse pelo que é discutido. É possível compreender que as problematizações de situações reais tornam-se o pontapé inicial na construção de uma educação dialógica e problematizadora, pois, a partir destas, os educandos inserem-se e sentem-se parte do processo de ensino/aprendizagem.

Muenchen (2010), ao discorrer sobre a importância da problematização, destaca que uma das características de problematizar é que os assuntos não são apresentados como fatos a memorizar, mas, sim, como problemas a serem resolvidos, sendo estes propostos a partir da experiência de vida dos educandos. E ainda, a problematização pode possibilitar que os educandos tornem-se críticos das próprias experiências, interpretando suas vidas, não apenas passando por elas.

A seguir, são apresentadas algumas das problematizações presentes nos planejamentos das aulas que foram construídas pelo coletivo do grupo e possibilitaram que o diálogo fosse construído entre educador-educando:

Que impactos o lixo depositado nas sangas de nossa cidade, bem com no Arroio Cadena $^{3}$ causam ao meio ambiente e a nossa saúde? Comente.

Para você, qual é o nosso papel como cidadão, para que os esgotos e alagamentos que ocorrem em nossos bairros, tendo como consequência várias doenças, sejam solucionados? Além de nós, existem outras pessoas responsáveis para que seja possível reverter essa situação? (PLANEJAMENTOS DE AULA).

Procurou-se, na elaboração das problematizações ${ }^{4}$, explorar as situações do contexto que os educandos encontram-se, pois, segundo Auler (2007), o ponto de partida no processo de ensino/aprendizagem deve ser construído por situações-problema, que sejam relativas a contextos reais e que estejam ligadas ao "mundo vivido" dos educandos. Constata-se, na fala de uma das docentes, a proximidade das problematizações com a vida dos educandos:

[...] eu coloquei a problematização, e eles se organizaram pra discutir como é que iam responder. E aí tinham muitos que são filhos de pedreiros né, e eu não tive que dizer "ó vão fazer", eles fizeram e se envolveram com aquilo, pois, o assunto era próximo da vida deles (Prof. 1).

\footnotetext{
${ }^{3}$ O Arroio Cadena é o mais importante curso de água da cidade de Santa Maria/RS o qual cerca 2/3 da cidade.

4 Torna-se importante pontuar, aqui, que as problematizações foram elaboradas pelas docentes a partir das compreensões obtidas por elas das discussões realizadas no processo formativo sobre perguntar e problematizar. Em nenhum momento as pesquisadoras apresentaram atividades já elaboradas. Dessa maneira, ao analisar os planejamentos das aulas, será possível constatar que existem aspectos que não se encontram em concordância com os referencias defendidos neste trabalho, mas, como se tratou de um trabalho coletivo, as diferentes visões fizeram-se presentes.
} 
Outro aspecto importante é apontado pela docente 2, a qual destaca que a problematização é o aspecto mais importante na dinâmica dos 3MP, conforme é apontado na fala a seguir:

O que é importante na dinâmica dos 3MP, uma das coisas importantes é a problematização com eles. Eu acho que é isso aí, a problematização, só que eu penso assim, que não só o que é da realidade deles, mas situações conhecidas por eles, vivenciadas. Situações que fazem parte do nosso dia-a-dia, mas, que muitas vezes tem coisas que não acontecem conosco que a gente sabe que faz parte da nossa sociedade enquanto cidade [...] Eu acho que é mais ou menos por aí, tu consegue trazer nas problematizações não só o que está na vivência deles e que é significativo pra eles, mas que parte da sociedade num todo, de situações que são reais, que acontecem às vezes longe da comunidade deles, mas, que atingem eles (Prof. 2).

Percebe-se, na fala da docente, que a mesma compreendeu a expansão que os 3MP apresentam a partir das problematizações, pois, esta dinâmica além de proporcionar um estímulo para a continuação da caminhada em busca de uma educação problematizadora e dialógica, possibilita, a partir da abordagem de temas que estão imersos na vida dos educandos e das problematizações construídas a partir destes temas, que as discussões iniciem em um patamar de nível local e adentrem em discussões de temas que se encontram a um nível de organização social mais amplo (TORRES, 2010).

\title{
O diálogo problematizador como potencializador da participação e do interesse dos educandos com base nos 3MP
}

Dentre as potencialidades, encontram-se o interesse e a participação dos educandos durante o desenvolvimento das aulas pelos temas abordados. Verifica-se isso nas falas a seguir:

\begin{abstract}
A interação dos alunos junto com os professores, em tudo assim. Cada um deu a sua opinião, porque esse tema que foi trabalhado todo mundo conhece um pouco, pelo bairro, ou que já ouviu falar por aí, em outros lugares de Santa Maria. Então, eu acho que foi muito interessante (Aluno 8).
\end{abstract}

Normalmente, alguns professores chegam e dão a matéria, daí dão o conteúdo né, e dão para a gente estudar. Daí a gente tem que fazer os exercícios, Mas não, não aconteceu assim, porque os professores, além de pedirem a nossa opinião, que na maioria das vezes não pedem né, eles interagiram, no caso conversando com a gente, nos explicando (Aluno 6).

É um tema do dia-a-dia, não é uma matéria nova né, que poucos sabem, é uma coisa que a pessoa usa, depende daquilo né. Ficava todo mundo dando opinião e todo mundo tem uma opinião sobre isso também (Aluno 10).

Eu achei interessante porque é uma coisa, que, no caso, todo mundo pode usar na casa né, é uma coisa assim, que tem na verdade no dia-a-dia das pessoas, que faz com que a aula fique mais interativa, faz com que todo mundo queria saber, entendeu? (Aluno 13).

Nas falas apontadas acima, percebe-se que os educandos demonstraram interesse e participação pelas aulas desenvolvidas pelos 3MP, pois estas exploravam os assuntos que estavam mergulhados em suas realidades, com isso, foi possível aguçar o que Freire denomina de curiosidade epistemológica. Para Freire, "é enquanto epistemologicamente 
curiosos, que conhecemos no sentido de que produzimos o conhecimento e não apenas mecanicamente o armazenamento na memória" (1994, p. 148).

Araújo e Muenchen, ao relatarem a postura apresentada pelos educandos durante o estágio docente, em que os 3MP direcionaram as aulas, apontam semelhanças com os aspectos acima mencionados:

A presença dessa curiosidade epistemológica demonstrada pelos educandos ocorreu, pelo fato de que a dinâmica utilizada dos 3MP tinha o diálogo e a problematização como seus principais instrumentos, o que propiciou ao aluno espaço para a participação, tornando-o sujeito ativo no processo de construção de seu conhecimento (2013b, p. 6).

Analisa-se, a seguir, o planejamento de uma aula. É possível perceber que o diálogo construiu-se a partir dos conhecimentos prévios apontados pelos educandos sobre situações vivenciadas por estes e o conhecimento científico abordado nesta aula:

Conteúdos: Densidade e Massa Específica ${ }^{5}$

Problematização Inicial

Para você, como podemos explicar o motivo de alguns objetos afundarem e outros não, quando abandonados em sangas e no Arroio Cadena? (Mostrar foto do Arroio Cadena, questionando-os sobre os objetos vistos por eles, e quais afundam e quais boiam).

Que impactos o lixo depositado nas sangas de nossa cidade, bem como no Arroio Cadena, causam ao meio ambiente e a nossa saúde? Comente.

\section{Organização do Conhecimento}

- Introduzir o conceito de densidade e massa específica. (Livro Hewitt)

- Após, como material de apoio, utilizar a simulação:

http://phet.colorado.edu/sims/density-and-buoyancy/density_pt_BR.html

Aplicação do Conhecimento

- Rediscussão das problematizações;

- Cálculo da densidade da água do Arroio Cadena. (PLANEJAMENTO DE AULA).

Dando prosseguimento a análise, foi possível perceber, também nas falas das docentes, em relação aos resultados obtidos com a utilização dos momentos pedagógicos, uma potencialidade em relação à interação e aproximação entre educador-educando, possibilitando uma satisfação e entusiasmo a partir do trabalho realizado. Destaca-se a seguir, uma fala representativa sobre os aspectos positivos em relação à dinâmica dos 3MP:

Eu acho que embora eu não me achasse tão longe deles, eu acho que essa maior aproximação foi que me levou a discutir situações da vida deles, que se eu não tivesse ido à comunidade eu não saberia né, como essa fragilidade social que eles

\footnotetext{
${ }^{5}$ Torna-se importante salientar que os conteúdos programáticos, na perspectiva aqui defendida, deixam de ser o fio condutor que definem os currículos escolares, que, por sua vez, apresentam características de currículos tradicionais que se encontram distantes e descontextualizados da realidade dos educandos e passam a serem construídos a partir de temas que surgem da realidade dos educandos. A partir disso, os conteúdos são elencados para que o tema abordado possa ser compreendido. No exemplo acima, de densidade e massa específica, estes foram necessários para a compreensão do tema Infraestrutura, que emergiu da realidade. Como consequência, os conteúdos tornaram-se os meios para o entendimento do tema e deixaram de ter o objetivo final em si próprios, como se verifica na prática de ensino que utiliza a educação bancária (FREIRE, 2011).
} 
têm. E aí, eu acho que forço uma aproximação maior, e essa aproximação maior tornou eles mais receptivos, embora eu acho que eu não tinha o que reclamar assim, mas ainda assim, com isso, parece que essa proximidade é mais forte, porque não é tão frágil se eu for comparar assim, "ah, eu conheço o meu aluno com aquilo que ele me diz que é a vida dele". Mas eu indo lá e vendo como é, é diferente a aproximação, parece uma aproximação mais verdadeira. Esse foi um dos pontos positivos (Prof. 1).

Pôde-se analisar nas potencialidades apresentadas acima que os 3MP, além de proporcionarem as docentes um espaço como atores principais na construção dos currículos e nos planejamentos das aulas com base nos temas que emergem desta dinâmica, oferecem uma relação muito próxima com os educandos, proporcionando-lhes discutir, participar, dialogar, avaliar e transformar a comunidade que se encontram, por meio dos temas que apresentam proximidades com seus contextos.

\section{Considerações finais}

Guerra (2013) ressalta que estas mudanças não se encontram atribuídas entre uma pedagogia de conteúdos ou uma pedagogia vazia de conteúdos, mas, sim, sobre quais os conteúdos que são propostos e com que metodologia eles são ensinados e aprendidos. Com isso:

\footnotetext{
Quaisquer que sejam as finalidades que amparam um projeto ou plano curricular, e ainda que se justificasse a seleção de determinados conteúdos, tudo isso acabará em uma construção inoperante de boas intenções se não conseguirmos provocar transformações internas nos que aprendem - processos ou ações mentais - para a aquisição de novos significados, sua organização e reelaboração, a transformação da maneira de pensar e de se comportar, o aperfeiçoamento da capacidade de argumentar e o aumento da conscientização em relação aos fenômenos que o rodeiam (p. 264).
}

Procurou-se com o desenvolvimento desta pesquisa romper com o tradicional ensino de memorização, extrapolando os limites de um ensino pautado por uma educação bancária (FREIRE, 2011), articulada a um ensino propedêutico e linear.

Como resposta ao problema de investigação, as potencialidades que resultaram da análise estão acompanhadas de uma mudança de postura apresentada pelos educandos, em que a participação, o interesse e a curiosidade pelos assuntos abordados fizeram-se presentes no decorrer das aulas, bem como, junto a todos estes aspectos, o diálogo problematizador construído entre educador-educando propiciou que as posturas iniciais, apresentadas no início do projeto, fossem passíveis de mudanças. Outro aspecto categorizado como uma potencialidade está submetido à necessidade que as docentes buscavam por um curso que proporcionasse discutir e refletir assuntos que iriam ao encontro dos objetivos da escola.

Cabe ressaltar que os resultados positivos não foram encontrados de maneira unânime, estes vieram acompanhados de grandes desafios e dificuldades, como: o trabalho coletivo e 
interdisciplinar, às condições de trabalho, à falta de tempo e aos reflexos impostos pela formação apresentada pelas docentes (ARAÚJO, 2015).

Contudo, mesmo com alguns desafios, os resultados foram satisfatórios, pois, ao constatar que os educandos apresentaram uma postura de participação, de interesse pelo tema Infraestrutura, possibilitaram que o diálogo problematizador permeasse as aulas e, que estes contribuíram para que as discussões fossem ricas de informações e visões, é possível perceber que trabalhos, como o que foi apresentado neste artigo, têm um papel transformador na educação, pois, a partir da utilização dos 3MP como estruturantes de currículos, bem como ferramenta metodológica, educador e educandos encontram-se numa relação horizontal de diálogo e saberes, sendo que o conhecimento apresentado por ambos é fundamental no processo de ensino/aprendizagem.

Ainda, com a utilização dos 3MP, "a participação do estudante e o seu cotidiano assumem um papel de destaque, [...] proporcionando à educação um avanço no que se refere ao ensino tradicional" (MUENCHEN; DELIZOICOV, 2012, p. 212).

Por fim, salienta-se que ao adotar referenciais como os mencionados neste artigo, é possível aproximar-se de uma educação pautada no diálogo e na problematização, potencializando uma relação mais próxima entre o "mundo da escola" e o "mundo da vida". Sinaliza-se, ainda, a continuação deste trabalho na própria escola e em outros locais, não restringindo as atividades realizadas à área das Ciências da Natureza.

\section{Referências}

ARAÚJO, L. B. Os Três Momentos Pedagógicos como Estruturantes de Currículos. Dissertação, (Mestrado em Educação em Ciências: Química da Vida e Saúde), Santa Maria: PPGECQV/CCNE/UFSM, 2015.

ARAÚJO, L. B.; MUENCHEN, C. O tema gerador 'Infraestrutura' e sua relação com o Pensamento Latino Americano em Ciência, Tecnologia e Sociedade (PLACTS). In: 3 SEMINÁRIO INTERNACIONAL DE EDUCAÇÃO EM CIÊNCIAS Internacional de Educação em Ciências, Rio Grande. Anais... Rio Grande, 2014.

ARAÚJO, L. B.; MUENCHEN, C. Um olhar sobre o Movimento de Reorientação Curricular: a posição dos docentes em relação ao projeto. In: VII SEMINÁRIO DIÁLOGOS COM PAULO FREIRE, Rio Grande. Anais... Rio Grande, 2013a.

ARAÚJO, L. B.; MUENCHEN, C. Alguns resultados da implementação do tema "Sol, Luz e Vida" durante o estágio supervisionado de Ensino de Física. In: V SIMPÓSIO NACIONAL DE TECNOLOGIA E SOCIEDADE, Curitiba. Anais... Curitiba, 2013b.

ARAÚJO, L. B.; NIEMEYER, J.; MUENCHEN. C. Uma análise dos trabalhos presentes nos Encontros de Pesquisa em Ensino de Física (EPEF): problematizações ou perguntas? In: IX CONGRESSO INTERNACIONAL SOBRE INVESTIGACIÓN EM DIDÁCTICA DE LAS CIENCIAS, Girona. Anais... Girona, 2013. 
AULER, D. Enfoque Ciência-Tecnologia-Sociedade: Pressupostos para o contexto brasileiro. Ciência \& Ensino, v. 1, número especial, novembro de 2007.

DELIZOICOV, D. La Educación en Ciencias y la Perspectiva de Paulo Freire. Alexandria: Revista de Educação em Ciência e Tecnologia, v. 1, n. 2, p. 37-62, 2008.

DELIZOICOV, D. Concepção problematizadora do ensino de ciências na educação formal. Dissertação de mestrado. São Paulo: IFUSP/FEUSP, 1982.

DELIZOICOV, D. Uma experiência em ensino de ciência na Guiné Bissau Depoimento. Revista de Ensino de Física, v. 2, n. 4, dez./1980.

DELIZOICOV, D.; ANGOTTI, J. A. P.; PERNAMBUCO, M. M. C. A. Ensino de ciências: fundamentos e métodos. São Paulo: Cortez, 2011.

FREIRE, P. Pedagogia do Oprimido. 50. ed. Rio de Janeiro: Paz e Terra, 2011.

FREIRE, P. Cartas à Cristina. 4. ed. Rio de Janeiro: Paz e Terra, 1994.

FREIRE, P. Pedagogia da Esperança: um reencontro com a pedagogia do oprimido. 16. ed. Rio de Janeiro: Paz e Terra, 1992.

GIACOMINI, A. Intervenções curriculares na perspectiva da Abordagem Temática: avanços alcançados por professores de uma escola pública estadual do RS. Dissertação, (Mestrado em Educação em Ciências: Química da Vida e Saúde), Santa Maria: PPGECQV/CCNE/UFSM, 2014.

GIL, A. C. Como elaborar projeto de pesquisa. 4. ed. São Paulo, Editora: Atlas, 2002.

GUERRA, M. A. S. O projeto de escola: uma tarefa comunitária, um projeto de viagem compartilhado. In: SACRISTÁN, L. G. (Org.). Saberes e Incertezas sobre o currículo. Porto Alegre, Penso, 2013, p. 248-280.

HALMENSCHLAGER, K. Abordagem de temas em Ciências da Natureza no Ensino Médio: implicações na prática e na formação docente. Tese de Doutorado (Programa de PósGraduação em Educação Científica e Tecnológica). Florianópolis: UFSC/PPGECT, 2014.

LINDEMANN, R. H. Ensino de química nas escolas do campo como proposta agroecológica: contribuições a partir da perspectiva freireana de educação. Tese de doutorado (Programa de Pós-Graduação em Educação Científica e Tecnológica).

Florianópolis: UFSC/PPGECT, 2010.

MORAES, R. Uma Tempestade de Luz: a compreensão possibilitada pela análise textual discursiva. Ciência \& Educação, v. 9, n. 2, p. 191-211, 2003.

MORAES, R.; GALIAZZI, M. C. Análise textual discursiva. Ijuí: Unijuí, 2007.

MUENCHEN, C. A disseminação dos Três Momentos Pedagógicos: um estudo sobre práticas docentes na região de Santa Maria/RS. Tese de Doutorado (Programa de PósGraduação em Educação Científica e Tecnológica). Florianópolis: UFSC/PPGECT, 2010.

MUENCHEN, C.; AULER, D. Abordagem temática: desafios na educação de jovens e adultos. Revista Brasileira de Pesquisa em Educação em Ciências. v. 7, n.3, p. 1-17.2007a, 
MUENCHEN, C.; AULER, D. Configurações curriculares mediante o enfoque CTS: Desafios a serem enfrentados na Educação de Jovens e Adultos. Ciência \& Educação, v. 13, n. 3, p. 421-434, .2007b.

MUENCHEN, C. Configurações curriculares mediante o enfoque CTS: desafios a serem enfrentados na EJA. Dissertação, (Mestrado em Educação), Santa Maria: PPGE/CE/UFSM, 2006.

MUENCHEN, C.; DELIZOICOV, D. A construção de um processo didático-pedagógico dialógico: aspectos epistemológicos. Ensaio: Pesquisa em Educação em Ciências, Belo Horizonte, v. 14, n. 3, p. 199-215, 2012.

PERNAMBUCO, M. M. Educação e escola como movimento: do ensino de ciências à transformação da escola pública. Tese de Doutorado. São Paulo: FEUSP, 1994.

PORLÁN, R.; MARTÍN, J. El diario del profesor: un recurso para la investigación en la aula. Sevilla: Díada, n. 6, 1997. (Coleção Investigación y Enseñanza).

RIO GRANDE DO SUL. Instituto Estadual Luiz Guilherme do Prado Veppo. Projeto Político Pedagógico. Santa Maria: 2011.

SAMPAIO, M. M. F.; QUADRADO, A. D.; PIMENTEL, Z. P. Interdisciplinaridade no município de São Paulo. Brasília: INEP, 1994.

SÃO PAULO. Cadernos de Formação 01, 02 e 03. Série Ação Pedagógica na escola pela via da interdisciplinaridade. Secretaria Municipal de Educação. São Paulo: DOT/SME-SP, 1990.

SAUERWEIN, I. P. S. A Formação Continuada de Professores de Física - natureza, desafios e perspectivas. Tese de Doutorado (Programa de Pós-Graduação em Educação Científica e Tecnológica). Florianópolis: UFSC/PPGECT, 2008.

TORRES, J. R. Educação ambiental crítico-transformadora e abordagem temática freireana. Tese de Doutorado (Programa de Pós-Graduação em Educação Científica e Tecnológica). Florianópolis: UFSC/PPGECT, 2010.

TORRES, C. A.; O’ CADIZ, M. P.; WONG, P. L. Educação e Democracia: A práxis de Paulo Freire em São Paulo. São Paulo: Cortez/Instituto Paulo Freire, 2002.

\section{SOBRE AS AUTORAS}

LAÍS BALDISSARELLI DE ARAÚJO. Licenciada em Física pela Universidade Federal de Santa Maria - UFSM (2012). Mestre em Educação em Ciências pelo Programa de Pósgraduação em Educação em Ciências: Química da Vida e Saúde da Universidade Federal de Santa Maria - UFSM (2015).

CRISTIANE MUENCHEN. Possui graduação em Física Licenciatura Plena pela Universidade Federal de Santa Maria, mestrado em Educação pela mesma instituição e doutorado em Educação Científica e Tecnológica pela Universidade Federal de Santa Catarina. Atualmente é professora Adjunta da área de Ensino de Física e dos Programas de Pós-Graduação: Educação em Ciências - Química da Vida e Saúde (PPGECQVS) e Educação Matemática e Ensino de Física (PPGEM\&EF) da Universidade Federal de Santa Maria. Coordena o Grupo de Estudos e Pesquisas Educação em Ciências em Diálogo (GEPECiD). É editora da seção Ensino da Revista Ciência e Natura, editada e publicada pelo Centro de 
Ciências Naturais e Exatas da Universidade Federal de Santa Maria. Tem experiência na área de Ensino de Ciências/Física, com ênfase em inovações curriculares, atuando principalmente nos seguintes temas: Abordagem Temática, Três Momentos Pedagógicos como Estruturantes de Currículos, Configurações Curriculares mediante o enfoque CTS e Práticas Freireanas no Ensino de Ciências.

Recebido: 20 de janeiro de 2017.

Revisado: 14 de abril de 2017.

Aceito: 24 de agosto de 2017. 